Henry de Montherlant, Rhadidja suivi de Sur une belle lépreuse, Alger, El Kalima, « Les Petits Inédits Maghrébins ", 2018, 103 p.

\title{
Gaëlle Cauvin
}

\section{(2) OpenEdition}

Journals

Édition électronique

URL : https://journals.openedition.org/coma/4192

DOI : $10.4000 /$ coma.4192

ISSN : 2275-1742

\section{Éditeur}

Institut des textes \& manuscrits modernes (ITEM)

\section{Référence électronique}

Gaëlle Cauvin, « Henry de Montherlant, Rhadidja suivi de Sur une belle lépreuse, Alger, El Kalima, «Les Petits Inédits Maghrébins », 2018, 103 p. », Continents manuscrits [En ligne], Comptes rendus de parutions, mis en ligne le 01 octobre 2019, consulté le 20 janvier 2023. URL : http:// journals.openedition.org/coma/4192 ; DOI : https://doi.org/10.4000/coma.4192 


\title{
Henry de Montherlant, Rhadidja suivi de Sur une belle lépreuse, Alger, El Kalima, « Les Petits Inédits Maghrébins ", 2018, 103 p.
}

\author{
Gaëlle Cauvin
}

1 Les Petits Inédits Maghrébins (PIM) publient des textes inconnus ou devenus introuvables en les éclairant d'une solide introduction. Leur premier ouvrage est L'Enfant fruitier, de Jean Sénac (2018), un manuscrit inédit du poète algérois, introduit par Guy Dugas, le directeur de la collection qui explique en détail la genèse de cet ensemble de poèmes et qui les présente dans une transcription conforme au manuscrit, maintenant les hésitations, les repentirs et les griffonnages des brouillons.

2 Pour leur sixième opus, les PIM ont fait paraître au printemps 2019 Rhadidja suivi de Sur les belles lépreuses de Montherlant. En fait, l'ouvrage réunit dix chapitres, presque dix inédits de l'auteur de La Rose de sables, le grand roman anticolonialiste écrit avantguerre en Afrique du Nord et publié seulement en 1968. Ces inédits - dont nombre de lettres - sont présentés encore une fois par Guy Dugas, avec cette même approche généticienne qui est la sienne et qui enquête sur les sources des textes littéraires.

3 Les deux principaux inédits qui font le titre de l'ouvrage semblent être à l'origine de deux romans de Montherlant : si la nouvelle «Rhadidja » annonce La Rose de sable, car l'on y reconnaît la belle indigène silencieuse qui changera à son insu le destin du jeune officier tout frais émoulu arrivé de métropole, on y reconnaît également Costals, l'écrivain à succès des Lépreuses, quatrième volume du roman cyclique de Montherlant Les Jeunes Filles paru en 1939. Une même source, deux textes. Qu'en est-il de cet amour entre une jeune fille locale et un métropolitain? C'est un amour libre, tellement libre qu'il se transforme en amour de la liberté. Ce qui transpire de cet attachement de Montherlant à l'Afrique du Nord, c'est cette liberté, comme il l'écrit dans cet autre inédit à forte dimension autobiographique, Homo Liber 1925. Texte augural de cette 
migration régulière de l'écrivain en Afrique du Nord, affamé d'exotisme, fuyant la vieille Europe, sa rigidité et ses tabous.

L'intérêt de cet ouvrage présenté par Guy Dugas est qu'un autre Montherlant que l'écrivain parisien se dessine. Un Montherlant avide d'informations pour ses romans à venir, un écrivain cherchant sa matière et pour qui seule la liberté prime : «L'écrivain, nous le savons, ne tenait pas à ce qu'on l'aimât, et même préférait qu'on ne l'aimât point, parce que ce non-amour laissait son cœur, son esprit et son temps libres. » Point d'amour, mais combien d'aventures? Cette citation est extraite de la nouvelle « Rhadidja » parue en 1939, et on peut la rapprocher d'une lettre de Montherlant à l'un de ses informateurs datant de 1930 : «Vous savez que je viens chercher ici la solitude, l'absence d'obligations, la possibilité de sortir inconnu, bref des conditions favorables au travail et le repos de l'esprit et du corps. » De 1925 à 1939, durant ces quinze ans en Afrique du Nord, il semble que Montherlant ait trouvé cette liberté nécessaire à la création.

5 Cette recherche de la liberté conjointe à celle de la créature n'est pas exempte de misogynie. Dans un manuscrit totalement inédit, intitulé « En Algérie » et écrit en 1931, la femme est comparée à un animal : "Oui, elle était ravissante. Ses prunelles noires immenses remplissaient presque toute la cornée, touchaient au bord des yeux, comme cela arrive aux animaux. » En 1931 encore, Montherlant demande à Claude-Maurice Robert, avec qui il est en correspondance: "Quelles sont au juste les délices de Tlemcen? " Ambiguïté vite résolue du choix du terme «délices». Il y a aussi cet amusant récit d'une dizaine de pages manuscrites qui compose la dernière section de l'ouvrage, l'un des premiers brouillons d'un chapitre non conservé de La Rose de sable, intitulé " Pour une étreinte avec F. ", où l'on suit les stratagèmes compliqués et quelque peu ridicules déployés par le héros pour rejoindre une bédouine.

6 La figure qui se dessine de Montherlant n'est pas forcément sympathique, on le voit passer d'une ville à l'autre, exécrant Oran et « la plèbe espagnole ", Tunis et « le magma judéo-bicot-sicilien ", faisant un scandale à Tlemcen, pressant ses informateurs. Son humour est parfois grinçant, son regard toujours acéré ; ils le rendent exigent et le font fuir, à la recherche de nouvelles aventures. Sur les «sentes de l'enchantement », selon l'expression de Guy Dugas, on le sent parfois se désenchanter. En fait, il nomadise en éternel insatisfait, jusqu'à sa renonciation finale, autant aux paradis maghrébins qu'à son œuvre La Rose de sable. Drôle de dénouement pour un homme qui, de Tunis à Tanger, est passé par nombre de villes, faisant part des caractéristiques locales avec une rare acuité, et souvent délicatesse.

7 Guy Dugas a retrouvé, dans le fonds Montherlant de la BnF, des fragments inédits où l'écrivain peint avec gourmandise le "décor» algérois: la terrasse du petit "bar Nelson ", rue Bab El Oued, ou bien les "grandes avenues pleines d'ombres" où il se tient après minuit à l'affût d'une rencontre charnelle, la grande ville innocente et sensuelle. Il se plaît aussi à l'évocation des couleurs de Tlemcen et de Sidi Bou Saïd, où il est question « de maisons en crème à la vanille, en crème à la framboise, en crème à la pistache, des bleus et des jaunes heurtés, des dessus de portes fleuris » et où la pluie révèle les couleurs : «Les verts, les blancs, les noirs délicats de la mosaïque du minaret reprennent leur valeur. Les vieux gris et les vieux jaunes... »

8 Dans ce court opus, se révèle ainsi un Montherlant magrébin, nomade et gourmand, «à l'œuvre » déjà, comme en témoignent ces esquisses, correspondances et fragments qui renseignent sur la genèse de ses grands romans à venir. 